\title{
LA ABDUCCION: POR LA SENSUALIDAD DEL PENSAMIENTO
}

Henry Portela Guarín

Profesor Facultad de Fisioterapia.

U. A. M.

a Escuela a través del transcurrir de la existencia humana, ha sido establecida como la generadora del desarrollo y modernización del país, saturada de compromisos políticos, económicos que atienden una ideología hacia la "movilidad social», hacia la estructuración de un capital capacitado en habilidades científicas, tecnológicas, además de culturales y socioeconómicas.

Sin embargo, ese proceso que posibilite acabar con todos los vacíos del hombre, propiciar la búsqueda del conocimiento y las alternativas de mejoramiento humano, está tergiversado en la filosofía institucional que la Escuela «maneja».

Rodrigo Parra Sandoval en su investigación «La Escuela Violenta» precisa que hay violencia física y verbal; la primera manifiesta en actitudes disciplinarias y de aprendizaje, la segunda exteriorizada en constantes regaños en diferentes momentos de la acción «Educati- 
va», hasta convertirse en estrategia metodológica para hacer pedagogía en el aula. Se ha olvidado así que en la Escuela, de la manera como viva la organización social, el poder de la autoridad, la justicia, el conflicto y el saber, se forja el ser humano. (1).

Luis Carlos Restrepo en su ensayo «El Derecho a la Ternura» ahonda precisamente en lo que está pasando con el discurso académico, diagnóstico de una problemática que sume la educación en un quehacer y un saber rígido, estigmatizado, sin emoción y profundamente racional.

Si el Derecho es poder que reglamenta las relaciones humanas, la ternura debe cruzar todas las motivaciones y

- Si el Derecho es poder que reglamenta las relaciones $\mathrm{hu}^{-}$ manas, la ternura debe cruzar todas las motivaciones $y$ acciones sentidas del hombre. acciones sentidas del hombre. Por ello resulta paradógico que la ternura sea desterrada del conocimiento, que la ciencia en su objetivización «cosifique» al ser humano en aras de mostrar avances y virtuosismos científicos.

Marcado positivismo, en que la Escuela dimensiona las pedagogías ascéticas (discontinuidad - oposición entre voluntad y deseo) y no reconoce las pedagogias hedonistas (desarrollan la posibilidad de formar una voluntad sin contraposición al deseo). (2)

Analizados así el saber y el hacer, se fortalecen en un auténtico racionalismo instrumental y el sentir se torna peyorativo, por una lógica discursiva de la guerra «los discursos deben acariciar sin perder su esencia» dice Luis Carlos Restrepo, en clara contraposicion a la pedantería del saber razonal, universal y apático.

La educación occidental entonces, se ha culturizado en lo visoauditivo, desconoce la integralidad del ser (cuerpo y mente) distanciados en un dualismo en que el cuerpo es «oprobio» es «tumba» y lo úníco válido es la mente como divinidad, verdad, salvación... cuerpos entonces que se ven, se oyen, pero no se tocan, ni se huelen, ni se sienten.

Excluir el tacto y el olfato del proceso pedagógico, es negar la posibilidad de fomentar la intimidad y cercanía afectiva en la relación educativa humanística, es perpe- 


\section{- Tampoco tiene sentido seguir per- petuando la escisión entre el conocimiento burocrático que trans- mite el profesor y un saber cotidiano mediado por las lógicas concretas ...}

tuar un distanciamiento corporal que entroniza el poder del «maestro» con un saber unidireccional, absoluto, irreflexivo, sin motivación, sin ESENCIA, porque no se enseña a buscar caminos, la información se da como sendero encontrado, como conocimiento definitivo.

La oposición Mito - Razón, desconoce la gran importancia de rescatar la aventura del intelecto para presuponer verdades, conjeturas como vías hipotéticas, sensibilidad como subjetividad generadora de opciones jugadas a la probabilidad o a la falacia.

Carlos A. Pinzón y Rosa Suárez en el V Congreso Nacional de Antropología en Villa de Leyva, 1989, plantean en su ponencia "Concepción del cuerpo en las sociedades no occidentales», el dualismo Naturaleza Cultura: La Naturaleza como lo heredado, lo orgánico de naturaleza física y bioquímica, y La Cultura como lo aprendido, opuesto a lo biológico, considerada entidad de la conciencia, representación lenguaje - escritura; es decir importa lo viso - auditivo, el sentir es intrascendente, no se articula.

Tampoco tiene sentido seguir perpetuando la escisión entre el conocimiento burocrático que transmite el profesor y un saber cotidiano mediado por las lógicas concretas, de las que nada se enseña en las aulas; no hay concordancia, entre lo que se 
aprende afuera (extraescolar) y lo que se aprende adentro (institución), cuando lo básico es que se pudiera reconceptualizar, y que esa preteoría se apropiara, se autoexplicara en los modos de comunicación escolar. (3)

Luis Carlos Restrepo invita entonces a que el proceso pedagógico se abra a la singularidad de las lógicas sensoriales (cogniciones afectivas), a reconocer los componentes pasionales del conocimiento, dinamizar afectivamente el ambiente educativo, deconstruir el analfabetismo afectivo, a fusionar la sensibilidad con las artes y la poesía pero también con la ciencia. Para ello plantea la teoría del error y la apertura epistemológica, la primera por posibilitar identidades (personales - profesionales - culturales y políticas) y la segunda por el cálculo de las diferencias, fundamentales para la captación de matices, variaciones y contextos (imaginación simbólica).

Si se reconoce el Núcleo Kinesico, lugar del conocimiento básico (TACTO - PROPIOCEPCION - SISTEMA VESTIBULAR) se podrá hablar del «cerebro social como fer- tilidad cognitiva», en constante abducción contra la aparente inocencia de los positivistas; por la resemantización epistemológica y por el encuentro de la huella GNOSEOLOGICA del contexto y la sensibilidad.

Si se educa en la ternura y para la ternura, se podrá formar en valores relacionados con la tolerancia social, se forjarán habilidades para convivir con las diferencias humanas (culturales racionales - religiosas - políticas...) y mediará el diálogo y la negociación para la resolución de problemas y conflictos.

(1) PARRA, Rodrigo; GONZALEZ, Adela; MORITZ, Olga Patricia y otros. «La Escuela Violenta». Editorial Tercer Mundo; Santafé de Bogotá, 1992. (2) MOCKUS, Antanas; HERNANDEZ, Carlos Augusto; GRANES, José y otros. «Las Fronteras de la Escuela». Punto Exe Editores, Santafé de Bogotá, 1994. (3) En las Fronteras de la Escuela. Se dilucida la articulación entre conocimiento escolar y extraescolar. Capítulo 2, pp 25 a 45. 